Cad. Est. Ling., Campinas, 46(1):121-130, Jan./Jun. 2004

\title{
EM TORNO DO CRIATIVO NA LINGUAGEM ${ }^{1}$
}

\author{
JÚLIA ALMEIDA ${ }^{2}$ \\ (Universidade Federal Fluminense)
}

\begin{abstract}
RESUMO Ce travail a pour objetif la présentation des différents conceptions autour de l'aspect créatif du langage en mettant en discussion le modèle recursif de la créativité proposé pour Chomsky. Contre un modèle de créativité qui supose la fixité de l'emsemble de départ qui se réalise prévisiblement à l'infini, la question de la créativité du langage serai posée ici à travers les travaux de Carlos Franchi, Sylvain Auroux e Gilles Deleuze, en remettant cette discussion à la question de l'histoire, mais aussi aux demandes sur le nouveau et l'imprévisible. Nous nous rapprocherons d'une manière de penser les objets de la connaissance - présente aujourd'hui dan les sciences et dans la philosophie - qui ne les prend pas comme constanttes et immutables, mais comme des systèmes où l'instabilité dynamique est immanente et créatrice.

Mots-clés Aspect créatif du langage; $N$. Chomsky; Philosophie de la différence.
\end{abstract}

Os leitores de Chomsky, mais ou menos aprofundados, devem ter todos se deparado em sua obra com visadas de um problema que é fundamental a seu modelo teórico: a questão do aspecto criativo ou criador da linguagem. Ao colocar como objeto de seu modelo a competência do falante, sob a forma de um sistema de regras que permitiria engendrar (isto é, enumerar explicitamente) um conjunto infinito de frases, está colocada a sua noção de criatividade lingüística, que seria representada por um esquema recursivo de engendramento infinito de expressões. Todos os termos com os quais monta seu modelo levam a marca deste aspecto criador da linguagem que está na base da competência lingüística: uma gramática científica desta competência-objeto do modelo seria, de modo semelhante a um algoritmo na matemática, capaz de apresentar o mecanismo finito (conjunto de instruções explícitas - de regras, elementos e categorias) capaz de engendrar um conjunto infinito de frases; também a linguagem é concebida tecnicamente como "um conjunto (finito ou infinito) de frases construídas a partir de um conjunto infinito de elementos" (Ruwet, 1975, p. 42).

Esta noção de criatividade lingüística, que interessa a Chomsky descrever, é chamada por ele de "criatividade governada por regras" e distinguir-se-ia, para este autor, de um outro tipo de criatividade, não tão interessante do ponto de vista do conhecimento do sujeito humano, designada como "criatividade que modifica regras". Enquanto a primeira

\footnotetext{
${ }^{1}$ Este artigo foi originalmente apresentado no V Congresso Nacional de Lingüística e Filologia, realizado de 27 a 31 de agosto de 2001, na UERJ, Rio de Janeiro

${ }^{2}$ Júlia Almeida é professora-visitante da Universidade Federal Fluminense e autora de Estudos deleuzeanos da linguagem (2003). E-mail: almeidajulia@uol.com.br.
} 
diz respeito à língua, à competência do falante enquanto sistema de regras, a segunda diria respeito à fala, à performance, aos múltiplos desvios individuais que poderiam suceder quando da realização da fala. É a "criatividade governada por regras" que caracteriza a atividade da linguagem como atividade infinita de um sistema de regras; seu estudo e descrição se assemelhariam ao estudo de aspectos de organismos finitos (tais como o cérebro humano) que podem ter atividade infinita (Ruwet, 1975, p. 46).

Segundo Chomsky, este aspecto criativo da linguagem, apesar de ter sido anteriormente vislumbrado por algumas gramáticas tradicionais ou estruturalistas, só pôde ser adequadamente tratado e descrito a partir do desenvolvimento de certas pesquisas em Lógica e Matemática, que tornaram possível formular um sistema de processos recursivos, isto é, ter "uma compreensão real do "modo como uma língua pode (nas palavras de Humboldt) 'fazer um uso infinito de meios finitos”” (Chomsky, 1965, p.88). O gerativismo, utilizando estes mecanismos técnicos, disponíveis na Matemática, de formulação de sistemas de processos recursivos, teria trazido à Lingüística a possibilidade de descrever a língua em termos de processos recursivos, isto é, através de regras que, por exemplo, ao reescreverem (ou substituírem) um elemento X, inserem X no interior delas mesmas, abrindo a possibilidade de se engendrar um número indefinido de expressões, pois elas podem aplicar-se um número indefinido de vezes (Ruwet, 1975, p. 45).

Esta apresentação sucinta do modelo de criatividade de Chomsky tem por objetivo destacar apenas as coordenadas que serão objeto de comentário nas reflexões sobre a criatividade apresentada a seguir, de modo a situar a concepção chomskiana em relação a alguns parâmetros: não se trata absolutamente da idéia de criatividade que diz respeito à criação ou à invenção nas artes e nas ciências, mas da criatividade normal, que faz parte do uso banal e cotidiano da linguagem (Chomsky, 1977, p. 92). Não se trataria também de uma criatividade relacionada aos desvios individuais e particulares, mas do processo construtivo ilimitado que antecede e permite qualquer uso da linguagem. Os processos criativos ou construtivos da linguagem assim propostos teriam tido na matemática o recurso técnico para sua apreensão, pelo esquema de construção infinita das expressões através de procedimentos recursivos, a partir dos quais pode-se descrever formalmente um sistema que faz um uso infinito de meios finitos.

$$
* * *
$$

Passemos agora à consideração deste aspecto criativo da linguagem pela ótica de Carlos Franchi. Em seu importante texto "Linguagem Atividade constitutiva", publicado inicialmente em 1977 na revista Almanaque e republicado em $1992^{3}$, Franchi nos apresenta uma visão bem mais abrangente desta criatividade da linguagem. Compartilhando com Chomsky a preocupação teórica que evita reduzir a linguagem ao papel de ferramenta social, limitando o trabalho científico à observação de sua face exterior, puramente instrumental, Franchi também procura destacar o aspecto construtivo da linguagem como uma atividade criadora, de quem é "agente e não mero receptáculo da cultura" que "temos

\footnotetext{
${ }^{3}$ É esta segunda versão que será referida neste artigo (In: Cad. Est. Ling., (22):9-39, Jan/Jun, 1992).
} 
Cadernos de Estudos Lingüísticos 46(1) - Jan./Jun. 2004

então que apreendê-la nesta relação instável de interioridade e de exterioridade, de diálogo e de solilóquio: antes de ser para a comunicação, a linguagem é para a elaboração; antes de ser mensagem a linguagem é construção do pensamento; e antes de ser veículo de sentimentos, idéias, emoções, aspirações, a linguagem é um processo criador em que organizamos e informamos as nossas experiências." (Franchi, 1992, p. 25)

A distância que Franchi toma de Chomsky se dá, entre outros aspectos, a propósito da reflexão sobre o que vem a ser este aspecto criativo da linguagem. Relendo Humboldt, Franchi procura refinar a compreensão da idéia humboldtiana de linguagem como atividade constitutiva, que "dá forma" às experiências mais do que as transmite, cuja função incessantemente criadora constitui e não se institui, "qualquer coisa de persistente mas a todo momento transitória", que "em si mesma, [...] não é um produto (ergon) mas uma atividade (energeia) [...] um contínuo esforço do espírito para articular o som de modo a torná-lo capaz de expressar o pensamento" (Humboldt apud Franchi, 1992, p. 29). Ora, como descrever a forma desta atividade constitutiva que seria a "forma da linguagem", como descrever as "propriedades deste processo 'em constituindo' que não se institui nos constituídos?" (Franchi, 1992, p. 31, 36).

A resposta não estaria junto de Chomsky, revela Franchi, pois "o modelo de chomskiano, operando sobre um conjunto fixo e determinado de categorias gramaticais [...] cuidando, enfim, da forma superficial das expressões, incide já, não sobre a atividade criadora da linguagem, no sentido humboldtdiano, mas sobre os resultados destas" (p. 31). Trata-se, em Chomsky, afirma, de descrever o produto da atividade (ergon) e não seu processo constitutivo (energeia), embora este lingüista afirme claramente, em algumas passagens, que desenvolva a idéia humboldtiana de linguagem. Não seria bem isto por esta leitura de Franchi, pois enquanto o modelo de Chomsky postula princípios, categorias estáveis e invariáveis que reiterando-se indefinidamente fornecem os meios ao conjunto ilimitado de atos particulares, em Humboldt, em nenhum momento, a linguagem apareceria como um processo de simples reiteração de formas estabelecidas:

E isso porque a forma em Humbodt designa os princípios dinâmicos do ato mesmo de "dar forma": designa a universalidade de um processo e não dos elementos variáveis que se tomam neste processo como suscetíveis de revisão e transformação. Designa um processo que não está sujeito a um conjunto estável e permanente de categorias, pois responde à provocação da imaginação; que constitui mas não se institui; que não se fixa, mas retoma e se renova. (Franchi, 1992, p. 31)

Rejeitando toda redução da linguagem a um sistema formal, Franchi mostra que a linguagem, na medida em que "dá forma", é uma atividade quase-estruturante, mas não necessariamente estruturada, quer dizer, uma organização estável de categorias, "o instrumento de uma prática primitiva de estruturação dos fatos da experiência, de revisão e reformulação" (1992, p. 32). O esquema chomskiano não dá conta, assim, de um dos aspectos fundamentais da linguagem, que é o de ser um meio de revisão de categorais e de criação de novas estruturas, um instrumento próprio de contínua retificação de todo o anteriormente organizado.

Desta divergência fundamental, aparecem duas imagens da criatividade: oposta à criatividade horizontal que emerge do modelo chomskiano e que se apresenta como 
construção das expressões mediante procedimentos recursivos que projetam ao infinito as mesmas categorias e elementos, Franchi propõe uma criatividade vertical da linguagem que não se reduz a um "pensar" e "significar" lógicos, mas que remete a um "pensar" e um "significar" analógicos, que "suportam o devaneio sem volta das similitudes e da metáfora, sem quadros fixos de valores, sem limites categoriais precisamente impostos, sem necessidade de conclusões" (1992, p. 27).

Tal criatividade vertical implica que as línguas naturais não tomem um domínio de interpretação semanticamente uno e coerente, como no caso de linguagens formalizadas, que se constituem "mediante uma série de restrições ao livre exercício da linguagem e mediante estrita 'contextualização' (lingüística) da significação" (1992, p.33). As línguas naturais existem antes de qualquer esforço delimitativo, trazendo a marca da indeterminação semântica, pois tornam "impossível a identificação dos objetos, nos vários sistemas de referência a que a linguagem se refere exclusivamente mediante recurso a especificações predicativas" (p. 34). Concluímos esta visita ao universo reflexivo de Franchi, com uma frase singular do autor, que abre espaço para pensarmos sobre a virtualidade da linguagem:

Pensamos que se tem privilegiado a linguagem (por sua aproximação às linguagens restritas dos sistemas formais) como instrumento de regularização e normalidade, limitando-se a sua virtualidade, quando um de seus aspectos (essencial) é o de prestar-se eficazmente à subversão das categorias e valores, à expressão da 'esquizofrenia' que cria universos encantados, poemas, teorias. (1992, p. 27).

$* * *$

Vamos agora introduzir a reflexão que faz Sylvain Auroux a respeito da criatividade lingüística. Auroux, no artigo "L'hytothèse de l'histoire et la sous-détermination grammaticale" (1994), esboça um modelo de superação da concepção que ele chama de "calculável ou recursiva" da criatividade e que seria sustentada por Chomsky, entre outros. Usando uma imagem da matemática, diz Auroux que se tomarmos como modelo de criatividade a imagem matemática de engendramento da sequiência dos números inteiros naturais (infinitos) a partir de zero, um e da função sucessor (regras finitas), nada dizemos sobre a emergência imprevisível de números irracionais, esta sim, segundo o autor, digna de ser considerada criativa, inventiva, e não simplesmente produtiva (produção ao infinito de inteiros).

Para este autor, a interpretação da criatividade lingüística enquanto se atém ao calculável e a regras inalteráveis passaria ao largo do que há de verdadeiramente criativo na prática da linguagem e fornece uma idéia simplista do comportamento lingüístico como simples possibilidade de produção e interpretação de um número infinito de frases a partir de um conjunto de regras finitas. O que o calculável, o predizível e a produtividade explicam do lingüístico não diria respeito absolutamente à criação; eles explicam o estabelecido, o estável. Contra este modelo que supõe a fixidez do conjunto de partida realizando-se infinita e previsivelmente, a questão do novo e do imprevisível se impõe para Auroux, "a questão - que toca tanto o ato de fala individual quanto a evolução histórica das línguas é saber de onde vem a capacidade de engendrar o 'novo'?' (1994, p. 27): como dar conta da inovação lingüística - aquela que quotidianamente invade o campo enunciativo, as 
Cadernos de Estudos Lingüísticos 46(1) - Jan./Jun. 2004

criações de novas estruturas, criações sintáticas, morfossintáticas, morfológicas (barbarismos, solecismos), variedades instáveis algumas acabando por se estabilizar, arranjos sintáticos e semânticos imprevisíveis que emergem na literatura, todo o lingüístico revolvido pela heterogênese de sua condição histórica? A esta pergunta o autor destinou o seguinte quadro teórico:

Já que a gramática, produtora de uma língua gramatical, isto é, qualquer língua engendrada por uma gramática, não é capaz de determinar o surgimento das inovações (comparáveis aqui aos números irracionais e não à simples produtividade de racionais) que se inscrevem, com a temporalidade, em uma língua empírica - esta supõe a eficácia e a irreversibilidade dos atos lingüísticos, a descontinuidade entre o que se passa antes e depois destes atos -, a maneira de incluirmos em nosso modelo os processos de inovação seria tratando desta língua empírica ou histórica. O que significa, para Auroux, supor um conjunto não-finito constituído pela reunião do (i) conjunto indefinido das emissões lingüísticas de grupos I de sujeitos falantes; (ii) conjunto indefinido das emissões de grupos que viveram antes de I, tais como, -I, -II, -III; (iii) conjunto das emissões dos grupos que viverão depois de I, ou seja, II, III, IV. A condição para a formação deste conjunto ou língua empírica é a intercompreensão de traços de emissões lingüísticas entre grupos que viveram períodos mais ou menos distantes.

Evidentemente, nenhuma gramática, sempre datada, poderia dar conta das mutações, da contingência e da impossibilidade de predição que implica a língua empírica, havendo necessariamente enunciados que com o tempo não seriam suscetíveis de ser engendrados pela gramática que lhes seria contemporânea. Daí a hipótese da subdeterminação das atividades lingüísticas pela gramática, isto é, a gramática não determina tudo, mas apenas bem pouco, de nossas atividades lingüísticas. A maneira de se dar conta da invenção neste tipo de atividade, contrária à construção de regras homogeneizantes da gramática, seria a construção de

modelos interativos, colocando em relação diferentes sujeitos com competências diferentes (eles têm histórias diferentes), em que a confrontação no tempo produz em cada um novas competências e a aparição de novas regras e de novas estruturas lingüísticas (1994, p. 30).

$* * *$

Vimos três modos de apreensão da questão da criatividade da linguagem e que se coloca para todas as línguas (Chomsky, Franchi e Auroux). Gostaríamos de introduzir, então, uma última perspectiva, a do filósofo Gilles Deleuze, a partir da qual iremos retomar e comentar pontos das concepções anteriores. Devemos notar que Deleuze nunca escreveu diretamente sobre este tema, como os outros lingüistas que apresentamos anteriormente. Mas há em sua obra inúmeras linhas que cruzam os temas da linguagem e do criativo, e o que faremos a seguir é apenas puxar alguns destes fios, articulando-os aos vieses propostos anteriormente, de modo a tentar fomentar a discussão do tema.

Para começarmos a explicitar as diferenças entre o pensamento de Deleuze e a concepção de Chomsky a propósito do aspecto criativo da linguagem, pareceu-nos interessante fazer uma incursão a dois modos de apreensão da noção de possível ou de 
ALMEIDA - Em torno do criativo na linguagem

possibilidade. É a partir da conexão de concepções distintas sobre o possível aos modelos de criatividade, que poderemos pensar, em sua radical divergência, o criativo chomskiano e o deleuzeano.

Vejamos, inicialmente, como a teoria gerativa concebe um "possível da linguagem" no sentido que precisaríamos examinar e confrontar. Em lingüística gerativa, o gramatical coincide com o que seria possível em uma língua, com o possível desta língua. O que quer dizer aí possível? De início, descartaríamos deste possível a idéia de correção ou de "interdição", isto é, a teoria gerativa não se dedica a um possível de convenção, aquele que, por exemplo, tratam as gramáticas escolares ou normativas - um possível jurídico. O possível gramatical não é tampouco o que é possível por jogo - um possível lúdico. Quando o lingüista é com ele confrontado - na poesia ou nos seus próprios exemplos agramaticais - é para melhor descobrir as regras que regem as formas gramaticais e aproximar-se, assim, do possível que o interessa. Segundo Mitsou Ronat (Prefácio a Chomsky, 1977, p. 11), o gerativista procura um "possível científico" que seria a "estrutura de todas as frases possíveis" ou o conjunto de regras que, restringindo as combinações seqüenciais de palavras, limita o campo de saber de uma língua e possibilita uma infinidade de formas linguageiras. Mas não se deve confundir este com outro "possível" científico. Chomsky $(1969$, p.19) evita toda aproximação da noção de "gramatical" enquanto conjunto de frases gramaticais possíveis em uma língua com a noção de probabilidade de ocorrência. Frase possível aqui não é frase provável - a que teria mais ou menos chances de ocorrer - já que não é o estudo estatístico de ocorrências que poderia determinar a "possibilidade" ou a "gramaticalidade" de uma seqüência.

Assim higienizado de outros usos da palavra, o possível no modelo de competência lingüística de Chomsky é estrutura ou gramática das frases possíveis e teria, segundo este autor, analogias com outras competências humanas, com, por exemplo, o modelo de competência da percepção visual que, fornecendo hipóteses sobre estruturas de base ou estruturas transformadas, engendraria "os rostos possíveis, e as transformações que diriam a que parece este rosto visto sobre todos os ângulos" (Chomsky, 1977, p.70). Outra analogia feita por Chomsky é com relação à música, em que as limitações biológicas determinariam a "classe de possíveis sistemas musicais humanos" (1977, p. 85). O lingüista também se refere a uma gramática universal - biológica - das sociedades possíveis, através da qual nos situaríamos em nossa sociedade, de certo modo inscrita nesta competência (1977, p. 86). Poderíamos seguir pensando modelos de competência que determinariam os possíveis em diversos domínios de atividades ou capacidades humanas. Em cada caso formalizaríamos o conjunto das limitações biológicas que responderiam pela possibilidade da aquisição e da realização infinita deste conhecimento.

De que maneira esta noção de possível que a teoria gerativa persegue ressoa um possível filosófico, ou antes, uma das apreensões do possível em filosofia, eis algo a ser investigado. Pensamos naquele conceito de possível que é concebido como antecedendo a realização, trabalhando como imagem prévia da realidade. Diríamos que este possível prévio se realiza assim como a competência lingüística é realizada em performances efetivas. Em filosofia, Henri Bergson foi quem se ocupou particularmente deste possível, ou antes, da crítica a este modo de apreensão do possível, como "possibilidade das coisas precedendo sua existência". Para ele, "no fundo das doutrinas que desconhecem a novidade radical de 
cada momento da evolução há muitos mal-entendidos, muitos erros", um deles seria o hábito de pensar a realidade precedida por uma possibilidade" (1970, p.109).

O que está aqui em oposição seriam dois modos de concepção da realidade: estaríamos entre "uma realidade que se cria imprevisível e nova" e uma "realidade precedida por uma possibilidade" - em que a realização acrescentaria "alguma coisa" à possibilidade mas nada de essencial, pois na realização há tudo que se encontra na possibilidade. Bergson concebe a crítica dos "possíveis que se realizariam por uma aquisição de existência” como a revelação de uma ilusão "imanente à maior parte dos filósofos", constituída por um dispositivo que realiza duas operações: remete a realidade para trás atribuindo-lhe um passado desde sempre possível; e antecipa-lhe um futuro como mera realização deste possível, para sempre lá.

O ponto em que poderíamos usar a crítica bergsoniana do possível, e sobretudo aquela que fará Deleuze em seguida, em relação à teoria gerativa, é no sentido de apontarmos as preferências desta teoria por um modelo de apreensão da realidade que nos propõe uma concepção da linguagem como sendo precedida por uma possibilidade que determina por antecipação tudo aquilo que pode acontecer. Neste regime de possibilidade, a criatividade é a simples passagem do possível ao real, a criatividade é a realização desta possibilidade prévia. Mas para ampliarmos o debate, vamos a Deleuze e a sua idéia de possível a partir de Bergson.

Pensar o possível e a criatividade com as lentes de Deleuze exige que, de saída, abandonemos este modelo de possibilidade que Bergson critica, como operação de retroprojetar um possível anterior assim que o real emerge e pesquisemos um outro modelo, cujos lances principais seriam:

- Ao contrário do precedente, o regime de possibilidade instaurado por Deleuze/Bergson faz depender o possível do acontecimento; ele só chega com o acontecimento. Não há possível prévio que determina o que vai acontecer; só há possível criado no lance mesmo do acontecimento.

- Estabelece-se, assim, uma distinção conceitual entre o possível que se realiza e a criação de novos possíveis: o primeiro nos traz um real pronto, preexistente, todo ele contido no possível prévio que se realiza mecanicamente. O segundo, o possível deleuzeano, faz irrupção no real como novidade emergente, ele se inscreve no real posteriormente ao acontecimento; não há possível prévio, dado, ele é justamente o que precisa ser criado. Resumindo este comentário com uma frase de Zourabichvili, quem tão bem tratou do possível em Deleuze: "o possível mudou de estatuto e recuperou sua figura autêntica, aquela positiva e virtual do ainda-não, em lugar da projeção irreal no futuro do já-lá" (1996, p. 16).

- De modo que não encontraríamos no real campos de possibilidades determinados lingüístico, visual, perceptivo, social - prévios, que nos forneceriam simplesmente alternativas já dadas para sua realização ao infinito. Estamos instalados no campo dos acontecimentos e, nele, os processos lingüísticos, visuais, perceptivos, sociais não são apenas possíveis-realizáveis. Os processos de linguagem, a visão, os esquemas perceptivos e as formas sociais, imersos em um campo aberto de relações e exterioridade, seriam 
ALMEIDA - Em torno do criativo na linguagem

como que forçados pelos acontecimentos deste campo, criam-se forçados, inventam-se e não raramente, fissuram-se em novos campos de possíveis, inventados no acontecimento.

Em certos aspectos, esta perspectiva não está distante dos comentários que Franchi e Auroux propuseram a respeito do modelo chomskyano. Em sua crítica ao filósofo, Franchi centrou-se no caráter histórico da linguagem no sentido preciso de ser um "processo que, reassumindo embora o material e as direções recolhidos do passado, recompõe aquele e reorienta estas" (1992, p. 29), ou ainda, "a atividade lingüística opera sempre sobre um substrato material já trabalhado anteriormente, fixado para determinados momentos, pelo que ela não se pode considerar somente uma produção sistemática e reiterada mas como sempre renovada reorganização" (1992, p. 33). Também em Auroux a questão se transfere para uma língua histórica, a inserção da linguagem numa temporalidade que supõe a irreversibilidade dos atos lingüísticos - entre antes e depois, algo se cria - e que garantiria um substrato para o surgimento do novo e para a própria criatividade da linguagem. De certa maneira, o acontecimento criando novos possíveis em Deleuze é também irreversibilidade, inserção numa temporalidade. Mas à diferença de uma simples sucessão de formas empíricas à maneira de Auroux - que faz suceder no tempo conjuntos lingüísticos, cI, cII, cIII ...-, a descrição desta criatividade em Deleuze partiria da idéia de uma instabilidade criativa permanente que afetaria o sistema, fazendo com que este difira sempre de si mesmo sem ser contudo um outro, uma variação imanente atirando as formas estabelecidas em uma tensão de futuro, sem que se possa assegurar a nova forma que se confecciona, apenas que ali algo se cria e se inova.

Em seu livro O nascimento do tempo (1988), o físico Ilya Prigogini, ao apresentar o modelo atual de ciência que o guia na compreensão dos sistemas dinâmicos, nos faz refletir sobre o modo como operamos cientificamente em lingüística. Alguns dos termos e das operações que parecem orientar esta disciplina, a predizibilidade, o desmonte das peças de um sistema, a idéia de que os sistemas devem ser analisados isolados de condicionamentos exteriores, a busca por condições ideais em que podemos encontrar constância e equilíbrio, tudo isto é problematizado pela termodinâmica recente, que trabalha com sistemas imprevisíveis, com conjuntos complexos, na interseção das relações entre sistemas e exterioridade (sistemas abertos), com estados e propriedades distantes do equilíbrio, em que a instabilidade dinâmica é criativa.

Este modo de pensar cientificamente os objetos do conhecimento, não através do que eles teriam de constante e de inalterável, mas do que apresentam de novidades e de instabilidades vai em sentido paralelo às indagações filosóficas de Deleuze, quando este propõe conceitos sobre a linguagem imantados de diferença e de variação. Sua idéia de diferenciação, quando conectada ao lingüístico, sugere um dinamismo contínuo atravessando a linguagem que não estaria do lado da fala, da performance, nem do lado de uma competência subjacente ou língua. Ao contrário, este dinamismo criativo da linguagem seria da ordem do virtual, atravessando estes dois domínios:

Será possível fazer gaguejar a língua sem confundi-la com a fala? Tudo depende, na verdade, da maneira pela qual se considera a língua: se a tomamos como um sistema homogêneo em equilíbrio, ou próximo do equilíbrio, definido por termos e relações constantes, é evidente que os desequilíbrios 
ou as variações só afetarão as palavras (variações não-pertinentes do tipo entonação...). Mas se o sistema se apresenta em desequilíbrio perpétuo, em bifurcação, com termos que, por sua vez, percorrem, cada qual, uma zona de variação contínua, então a própria língua põe-se a vibrar, a gaguejar, sem contudo confundir-se com a fala [...] (Deleuze, 1993, p.139).

É evidente que esta colocação da instabilidade criativa como aspecto essencial de um sistema não resolve tecnicamente o problema que Franchi havia apontado sobre a linguagem, de "como dar conta da 'forma' dessa atividade, ou das propriedades desse processo ‘em se constituindo' que não se institui nos constituídos?” (1992, p. 36). Mas sugere termos que orientam a busca deste aspecto criativo da linguagem em um sistema aberto, cuja instabilidade é imanente e produtiva, criando possíveis (gramaticais, lexicais, prosódicos...) exigidos pelos problemas internos e externos - acontecimentos - que a forçam a dizer. Deleuze e Guattari deixam também o caminho aberto para uma releitura de Hjelmslev e de sua "teoria espinozista da linguagem", que começa pelo reconhecimento das interdependências ou funções articuladoras, imanentes, a partir do que se constituem as formas, e não por entidades prévias, transcendentes, do tipo significante-significado (Deleuze \& Guattari, 1972, p. 288). É curioso que Franchi também tenha se referido a Hjelmslev e a seu uso das noções de função e de dependência ao apresentar instrumentos "para tentar uma aproximação da forma interna da linguagem, superando a dicotomia som-sentido, estrutura semântica-estrutura sintática, apagada na consideração da atividade que a constitui" (1992, p.37). Mas aqui paramos com as nossas conexões de idéias e de autores, pois caberia a um outro trabalho investigar esta idéia de função como propícia a avançar nesta discussão essencial em torno do aspecto criativo da linguagem.

\section{REFERÊNCIAS}

ALMEIDA, Júlia. (2003). Estudos deleuzeanos da linguagem. Campinas: Ed. Da Unicamp.

AUROUX, Sylvain. (1994). "L'hytothèse de l'histoire et la sous-détermination grammaticale". Langages, ${ }^{\circ}$ 114 , jun.

BERGSON, H. (1970). Oeuvres: pensée et mémoire. Paris: PUF.

CHOMSKY, Noam. (1965). Aspects of the Theory of Syntax. Cambridge: MIT Press. (1969). Structures Syntaxiques. Paris: Seuil. (1977). Dialogues avec Mitsou Ronat. Paris: Flammarion.

DELEUZE, Gilles. (1993). Critique et Clinique. Paris: Minuit.

DELEUZE, G. \& GUATTARI, F. (1976). O anti-édipo. Rio de Janeiro: Imago.

FRANCHI, Carlos. (1992). "Linguagem - atividade constitutiva”. Cadernos de Estudos Lingüísticos, n 22 , Campinas, pp. 9-39.

PRIGOGINI, Ilya. (1988). O nascimento do tempo. Lisboa: Edições 70. 
ALMEIDA - Em torno do criativo na linguagem

RUWET, Nicolas. (1975). Introdução à gramática gerativa. São Paulo: Perspectiva.

ZOURABICHVILI, François. (1996). “Deleuze et le possible (de l’involontarisme en politique)”. Comunicação apresentada nos Encontros Internacionais Gilles Deleuze, Rio-São Paulo, mimeo. 